\title{
DEVELOPMENT OF TEACHING MODELS THAT ENHANCE THE SCIENTIFIC REASONING CAPABILITIES OF SENIOR HIGH SCHOOL STUDENTS
}

\author{
Sawangjit Treeporn, Asst. Prof. Dr. Decha Suppapittayaporn, \\ Assoc. Prof. Dr. Virapong Saeng-Xuto and Asst. Prof. Dr. Kreetha Kaewkong \\ Ph.D. Candidate (Education), Faculty of Education, Chiang Mai University, Thailand \\ DOI: 10.46609/IJSSER.2021.v06i02.012 URL: https://doi.org/10.46609/IJSSER.2021.v06i02.012
}

\section{ABSTRACT}

This research aims to 1) create a teaching model that enhances the scientific reasoning capabilities of senior high school students, and 2) study the effect of using teaching patterns on the ability to reason scientifically.Samples include fourth-grade students at Phusangwittayakhom School in Phayao Province, 14 persons in the second semester of the academic year 2019.This is obtained by a specific selection of research instruments include teaching formats and a measure of the scientific reasoning capabilities of curved motion, and analyze the data by looking for averages, standard deviations, and finding influence sizes. The results showed that the improved teaching model consisted of (1) principles, (2) aim, (3) the four learning processes include concept test, observation, discussion, elaboration, and discussion, and (4) measurement and evaluation. The results of a teaching model that enhanced the ability to reason scientifically showed that projectile 1 movement had an influence size of 2.0, projectile 2 movement has an influence size of 2.1, horizontal circular movement the influence size is 1.7 , and vertical circular movements, the influence is 0.5 .Considering the composition of scientific reasoning as a whole, it found that claims were the most identifiable element of 75.77 , followed by evidence accounted for 54.08 percent, and reasoning accounted for 20.92 percent respectively.

Keywords:Teaching Models/ Teaching Science / Scientific Reasoning

\section{Introduction}

One of the goals of science is to explain the natural phenomena that occur on earth. So scientists are trying to understand how those phenomena occur and why they happen. The whole description begins with the need to find answers to questions by creating claims, to test different claims. Therefore, scientists often design and conduct surveys by collecting data or using existing data, and use rational thinking to show why the evidence supports or opposes such 


\section{International Journal of Social Science and Economic Research}

ISSN: 2455-8834

Volume:06, Issue:02 "February 2021"

claims. By creating an explanation of the natural phenomenon, scientists use the argument to debate the claims, to assess the accuracy of the claims and the evidence used in the support (Krajcik \& McNeill, 2015). Which the relationship between evidence and claims is at the heart of scientific reasoning (Lee \& She, 2010; She \& Liao, 2010; Engelmann, Neuhaus, Fischer, 2016), teaching students to use scientific reasons allows students to compare science with other perspectives, it is a possible way to make arguments and decisions on social issues related to science (Develaki, 2017). By learning science, scientific reasoning is one of the key capabilities and an element of learning skills in the 21 century that was defined as the primary focus on the standard of education in science, as it not only affected the academic achievement of students in school learning, this also influences everyday decisions and achievements in the lives of students. (Ding, Wei, \& Mollohan, 2016; Ibrahim, Ding, Mollohan, \& Stammen, 2016; Zhou et al., 2016)This, knowledge of scientific processes and concepts, knowledge application skills, and the ability to reason scientifically enough to enable people to take advantage of scientific data. Therefore, enhancing scientific reasoning is highly relevant for science education and lifelong learning. (Engelmann et al., 2016) Inhelder and Piaget (1958 referred to in Fabby \& Koenig, 2015). It has been pointed out that, naturally, students will develop the ability to reason when they are advancing in learning, although basic reasoning skills begin to develop from the age of 4 years old, the ability to give scientific reasons generally begins to develop during adolescence or age 11 to 15 years. At this age, children begin to have more complex logical ideas and take into account a variety of variables in solving problems, understanding physical and social phenomena. However, there is a lot of research that shows that students at secondary and university levels have low levels of scientific reasoning. (Marusic \& Slisko, 2012)As Jufri, Setiadi, and Sripatmi (2016) studied the scientific reasoning of teachers in year 2-3 of Mataram University in Indonesia, a total of 179 people used Lawson's (2000) classroom test of scientific reasoning, it found that 95.5 percent of students had low ability to give scientific reasons. As well, Marusic and Slisko (2012) used scientific reasoning professed measurements (LCTSR), according to Lawson's guidelines (2000), to study the scientific reasoning capabilities of senior high school students in the Republic of Croatia, 178 people received different teaching methods. In this regard, less than 20 percent of students with high levels of scientific reasoning were found to be high.In line with the study report, the study trends, management, education, mathematics, and international science (TIMSS). This assesses learning habits in 3 aspects of mathematics and science; this includes knowledge, application of knowledge, and reasoning. In 2015, a secondyear student's reasoning assessment in science found that 19 countries participated in the survey. For Thai students, an average score of 447 was lower from 2007 to 2011, students can't answer the question clearly and don't answer the question, and they can't write an explanation that requires reasoning (Science and Technology Teaching Institute, 2017). That's because science is still more focused on content than reasoning, students lack involvement in proving their claims 


\section{International Journal of Social Science and Economic Research}

ISSN: $2455-8834$

Volume:06, Issue:02 "February 2021"

in science classes (Marusic \& Slisko, 2012; Martin, Mullis, Foy, \& Stanco 2012) students write unsubstantiated claims and cannot find evidence in line with their claims (Berland, McNeill, Pelletier, \& Krajcik, 2017).

In teaching physics, there are many opportunities to teach scientific reasoning so that students can develop scientific reasoning, by using physics concepts and principles to describe natural events and solve both quantitative and qualitative problems (Zhou et al., 2016). Also, the physics problem is complex and requires students to integrate their knowledge into existing content together with critical thinking to determine what the problem is. It found that students with high reasoning ability would perform a good solution by applying concepts and physics principles in the solution process (Fabby \& Koenig, 2015).However, the physics teaching process in the school it's not about cultivating knowledge and physics concepts, but it's a teaching that focuses only on a certain moment. As a result, students lack educators to understand the content or core concepts they have learned, when students answer relevant questions in reasoning, they are asked to answer questions related to reasoning. This suggests that students are shown to be misleading or inconsistent with scientific explanations (Institute for the Promotion of Teaching science and technology, 2011).Because many physics teachers think they can teach scientific reasoning without students having to engage in scientific activities. Therefore, the student's scientific reasoning is not practiced (Marusic \& Slisko, 2012). Several types of research show the relationship between a student's misguided concept and the ability to reason science. These studies have found that students with good scientific reasoning skills have less misleading concepts, and students with high levels of reasoning are more likely to change their misleading concepts more easily (Lee \& She, 2010).Piaget (1985 referred to in Marusic \& Slisko, 2012) says that in a person's learning, two different processes occur, that is assimilation is a process in which a person uses an existing cognitive structure to understand new events and to restructure their intelligence. This is a current cognitive restructuring to reinterpret your experience or situation. When students experience new experiences for the first time, they will try to understand new experiences using the same knowledge. When it appears that it is not suitable for existing knowledge structures, cognitive imbalances or intellectual conflicts occur. Therefore, students will need to adapt their concepts until they can integrate new experiences into the original experience. The process of structuring existing concepts and knowledge is especially important for learning physics and is the cornerstone of conceptual change; because students are at the heart of reflecting the results of teaching, teachers should therefore create learning scenarios that encourage students to express their ideas. Vygotsky (1986, referred to in Marusic \& Slisko, 2012) explains that individuals develop an understanding of the concept through social interaction and controversy with collaborative learning. Therefore, in the science class should be a group activity that provides an opportunity to discuss concepts, make assumptions, and determine how to test that hypothesis. In particular, instructors should facilitate the development 


\section{International Journal of Social Science and Economic Research}

ISSN: $2455-8834$

Volume:06, Issue:02 "February 2021"

of understanding the student's concept by presenting problems that cause intellectual conflict and highlighting how well scientific concepts can explain the phenomenon. The purpose of teaching is to modify students' misguided concepts using accurate scientific evidence (Dennick, 2016) by, students' misconceptions are found in physics, astronomy, biology, and chemistry. However, the most misleading subjects of students are physics in the content of mechanics (Taasoobshirazi \& Sinatra, 2011).

The relationship between teaching methods and the development of scientific reasoning is widely studied and demonstrates that learning science based on the quest for knowledge, promotes the ability to use scientific reasons (Zimmerman, 2007; Bao et. al, 2009), scientific reasoning is therefore an application of the scientific research process in reasoning situations (Piekny \& Maehler, 2013). The characteristics of the pursuit of knowledge are that students are involved in scientific questions, students focus on evidence in scientific responses, where students create evidence-based explanations to answer scientific questions, and students associate them with scientific knowledge, as well as students to communicate and reason for their findings (National Research Council, 2000; Wilson, Taylor, Kowalski, \& Carlson, 2010). Therefore, in the search process, teachers can support students in developing scientific reasoning by clarifying the elements and importance of scientific reasoning, including claims, evidence, and reasoning, by linking scientific reasoning to everyday life and exemplifying scientific reasoning (McNeill \& Krajcik, 2008). For example, Mirko and Josip (2012), who developed reading, presenting, and questioning (RPQ) and experimenting and discussion (ED), want students to participate in learning, such as knowledge quest, argument, explaining, and modeling, these methods allow students to test their claims and develop knowledge to understand the nature of science. Which, using the teaching method RPQ, allows students to choose to read the articles that teachers have prepared for, and students read to understand the problem and search for more information from online sources to find solutions from the article that reads, and then present the class page to friends to ask additional questions on issues that are not yet understood. In the initial ED teaching section, teachers explain experiments to students without actually conducting experiments. But students have to predict possible experimental results.In this regard, the students must note the predictable results and physical descriptions in their notebooks and present predicted results. This, in Mirko and Josip's research, shows that teaching physics is a lecture, it contributes little to the development of a student's ability to give scientific reasons and is better for developing scientific reasoning that allows students to experience cognitive conflicts from directly observed experiments, and the key focus of the teaching model developed by Mirko and Josip, it not only emphasizes the development of the ability to give scientific reasoning but also emphasizes social interaction by learning together between peers in physics classes to increase the level of ability to reason scientifically. In line with Jensen and Lawson (2011), this found that the study was based on learning cycles. This is a method of teaching 
International Journal of Social Science and Economic Research

ISSN: 2455-8834

Volume:06, Issue:02 "February 2021"

based on constructivism theory, which is more effective in leading to understanding concepts and scientific reasoning than lecture teaching.

From the observation of teaching physics in Phusangwittayakhom School, teachers were found to use educational methods following the institute to promote teaching science and technology. However, the teaching activities do not emphasize that students can rationally answer questions. Students are not aware of the use of evidence to support the claims. When students give reasons to explain the physics phenomenon, they are encouraged to use the Students will give reasons based on their understanding. Therefore, the ability to give scientific reasons is not practiced. For such reasons and importance, therefore researchers are interested in developing teaching patterns that enhance the scientific reasoning capabilities of high school students using constructivism theory and scientific pursuit as the basis for development, to help students build their knowledge and restructure their knowledge, it can be applied to real-world events in everyday life and further enhance the efficiency of teaching scientific reasoning.

\section{Research Objectives}

In this research, the objectives are: (1) to create a teaching model that strengthens the scientific reasoning capabilities of senior high school students, and (2) to study the effect of using teaching patterns on the ability to reason scientifically.

\section{Methodology}

To create a teaching model that enhances the ability to provide scientific reasoning, the researchers conducted a two-phase developmental research methodology based on the following research objectives:

\section{Phase 1: Creating a teaching model that strengthens the ability to provide scientific reasoning.}

The researchers created a teaching model that enhanced the ability to provide scientific reasoning as follows:

\section{Step 1: Study the basics related to the development of teaching models}

1. Study the current state of teaching physics in the field of scientific reasoning, as well as the learning activities of the learner, and the difficult conditions of teaching the physics of the instructor at the high school level, by collecting information from documents, research and observations during physics teaching, the study results are used to determine the approach to the development of learning management. According to the study and observation, in teaching physics, teachers still use lecture teaching, the teaching process focuses on remembering and 
International Journal of Social Science and Economic Research

ISSN: 2455-8834

Volume:06, Issue:02 "February 2021"

responding over time, by taking note of the content and listening to the teacher's description, the learner lacks an understanding of the main content or concepts learned, and when the learner answers relevant questions in reasoning, the learner provides reasons that are inconsistent with the scientific explanation.

2. Study concepts, theories, and research related to scientific reasoning, the development of teaching patterns, teaching science along with constructivism, and knowledge quest, and then synthesizing for use in the design of teaching models.

\section{Step 2: Designing and developing teaching models}

1. Design a teaching model by defining the composition of the teaching model and the assessment method.

2. Create a teaching model using synthetic information in step 1, which provides a teaching model with elements such as principles and aims, and the four learning processes, including step 1 concept test, step 2 observation, step 3, discussion and reasoning, and step 4 elaboration and evaluation.

3. Define workshop definitions and criteria to measure the ability to scientific reasoning based on the composition of scientific reasoning, based on the scoring framework of McNeill and Krajcik (2008).

4. Prepare a learning management plan based on the teaching model, using the content of the curved movement 12 lessons. This is divided into projectile movement's total of 6 lessons, and horizontal circular movement's total of 4 lessons and vertical circular movements total 2 lessons.

5. Check the quality of the teaching model and the expert plan has the IOC value between $0.80-$ 1.00 .

\section{Step 3 Teaching model experiment}

The researchers conducted a pilot study in which they experimented with a code-based learning management plan with fourth-year students at Phusangwittayakhom School, semester 2, the academic year 2018, which is not a real sample, by conducting a trial of the learning management plan according to the CODE teaching model for 2 times. The researchers conducted their instruction to determine the suitability of the content, time of the study, learning activities, evaluation measurements, problems, and obstacles that arise throughout the course.

\section{Step 4 Teaching model evaluation}


International Journal of Social Science and Economic Research

ISSN: 2455-8834

Volume:06, Issue:02 "February 2021"

Improve the model and learning management plan using information from post-teaching records obtained from pilot studies.

\section{Phase 2: Studying the effects of the use of code teaching models on scientific reasoning.}

In a study of the effect of the CODE teaching model on scientific reasoning, the researcher performed the following actions:

1. Study documents related to measuring the ability to provide scientific reasoning from international tests and related research, to analyze the curriculum, learning materials, and physics of curved motion from the course description, to determine the point of measuring scientific reasoning on various topics and the number of subjects of the quiz.

2. Create multiple choice questions with 2-5 choice, 4 scenarios, and open-ended questions for students to write, justifying their choice, obtained a total of 28 tests. It is divided into a projectile movement for 2 scenarios, 15 tests, horizontal circular motion, 1 scenario 8 tests, and vertical circular motion for 1 scenario 5 tests.

3. Take the test with a content accuracy assessment to 5 experts to evaluate and provide feedback. Which, the IOC found, is between $0.8-1.00$, then the researchers performed a test correction based on the expert's instructions as follows:

4. Take the improved test to the 5th-grade students of Phusangwittayakhom School, semester 1, and academic year 2018, of which 30 students have already learned about curved mobility. To determine the classification power, difficulty, and confidence, the confidence of the multiplechoice test was 0.85 , the classification power value was between $0.24-0.56$, and the difficulty value is between $0.20-0.74$, the subjective test confidence is 0.89 , the value is between $0.24-$ 0.56 , and the difficulty value is between $0.20-0.74$.

5. Conduct a pre-test with sample students, by using a test to measure the ability of scientific reasoning about the arc movement created by the researcher.

6. The researchers conducted a lesson in the development of the learning management plan, which took 3 weeks, 4 sessions per week for a total of 12 lessons. Then evaluate the course between the work and the workload that students do in each period.

7. After learning management, the researchers conducted a post-test using a test to measure the scientific reasoning capabilities of curved motion created by the researchers. 


\section{International Journal of Social Science and Economic Research}

ISSN: $2455-8834$

Volume:06, Issue:02 "February 2021"

8. Find the average, percentage of the average, standard deviation, of the score from the test, and compare the scientific reasoning capability score between before and after the trial group, using its formula Cohen's d (1988).

\section{Concept and Theory}

The development of teaching models that enhance the scientific reasoning capabilities of high school students, the researchers studied concepts, theories, and related research, as follows:

\section{Ability to give scientific reasons}

In studies on the use of scientific reasoning, meaning can be divided into 3 perspectives, as follows:(Engelmann et al., 2016).

Group 1: because of the process of scientific discovery by providing scientific reasons in this view, begins by observing an inexplicable phenomenon, various assumptions, and hypothetical tests (Lawson, 1985), on its side Zimmerman (2007) has said that broadly defined scientific reasoning is the thinking and reasoning skills associated with the pursuit of knowledge, experimentation, evidence assessment, inference, and argument, that result in changes in conception or scientific understanding, and Bao et. al. (2009) said that scientific reasoning is a competency related to critical thinking and reasoning, the ability to systematically identify problems, create and test assumptions, manipulate and digest variables, observe and evaluate them. However, Lawson (2010) says that scientific reasoning refers to the idea of a person using it in the pursuit of scientific knowledge, starting with exploring natural phenomena, questioning the cause, making assumptions, predicting what will happen, empirical evidence collection, until scientific conclusions can be concluded. As well, Fischer et al. (2014) say that scientific reasoning is a capability that is carried out by the use of skills such as planning, conducting, and evaluating scientific audits or the use of scientific models.

Group 2: In perspective, focus on arguments or the creation of scientific explanations, it is a rationalization process in a scientific perspective, by using evidence to support the claims, on the other hand, McNeill and Krajcik (2008) say, scientific reasoning is explained using scientific principles to show the link between evidence and claims, and Lee and She (2010) say that scientific reasoning is a process to draw conclusions based on principles and evidence, it begins with the original knowledge that a person already has led to the creation of new conclusions. As well, Osborne (2010) said that scientific reasoning is an attempt to establish the truth by showing a link between the claims and the evidence associated with the claims.As well as Gotwals, Songer, and Bullaed (2012), it means that scientific reasoning provides an explanation that uses scientific principles to show why information is evidence in support of claims, in line with Yang 


\section{International Journal of Social Science and Economic Research}

ISSN: $2455-8834$

Volume:06, Issue:02 "February 2021"

and Wang (2014), explains that scientific reasoning refers to the use of logic to link the relationship between evidence and claims.

Group 3: In perspective, related to the natural understanding of science covering concepts, values, and conclusions, it is considered important of scientific knowledge. Which, students' understanding of the nature of science, as well as the concept of science, has long been a goal in science studies in many countries. In this view, scientific reasoning is associated with scientific thinking, this is a thought process based on the rationality and consistency of empirical evidence used in the quest for knowledge, to lead to answers to questions or problems, accurate and reliable (Kuhn and Pearsall, 2000; Peters, 2012). By, Giere (1991) says, scientific reasoning refers to thinking that is based on the processing of general principles with concrete examples, lead to scientific discoveries, it also helps to understand and evaluate scientific data for life and work.As well as Zeineddin and Abd-El-Khalick (2010), scientific reasoning is a thought process that involves researching the cause until it is inferred to reach its conclusion.

For this research, the researchers studied the perspective of argument or the creation of scientific explanations. Therefore, scientific reasoning refers to the ability to use scientific principles to provide explanations to link the relationship between evidence and claims.In the study of the composition of scientific reasoning because of arguments or the creation of scientific explanations, it was found to be based on the controversial form of Toulmin (2003), which has the following elements:

1) Data refers to facts related to the issues that arise in the dispute for use, supporting claims.

2) Claim means a conclusion that leads to an argument.

3) Warrant means a reason, rule, a principle proposed to make a connection between the data and the conclusion or claim credible or reasonable.

4) Additional support reasons (Backing) refer to a generally accepted preliminary agreement to build credibility for reasons to support warrants.

5) The supplementary condition (Qualifier) refers to what indicates the condition or circumstances that make it believe that the claim is true.

6) Rebuttal refers to the circumstances or conditions that make the claim untrue.

For example: Invite students to explain and reason about the temperature of certain objects, such as metal and wooden spoons that are placed in the same room for the same time. Students explain and reason as follows:

"I think all objects in the same environment have the same temperature (claims) even if the object has its thermal energy (auxiliary condition). This is true because in the laboratory 
International Journal of Social Science and Economic Research

ISSN: 2455-8834

Volume:06, Issue:02 "February 2021"

we set the temperature to 20 degrees (data), which proves that the temperature of the room changes the temperature of the object, to the room (the reason supporting the claim)."

McNeill and Krajcik (2008) used to frame the controversial concept of Toulmin (2003) developed as a conceptual framework for creating scientific explanations that focus on reasoning, the following elements are as follows:

1) Claim refers to the conclusion of a question or issue related to the phenomenon.

2) Evidence refers to the scientific data used to support the claim, which is derived from the pursuit of the student's knowledge or other sources, such as observation, reading of relevant documents, and must be appropriate and sufficient to support the claim.

3) Reasoning means explaining why the evidence supports the claims.

For example:

Question: Based on the information in the table, students identify which liquid is the same substance.

\begin{tabular}{c|c|c|c|c}
\hline & Density & Color & Mass & Melting point \\
\hline Liquid Type 1 & $0.93 \mathrm{~g} / \mathrm{cm}^{3}$ & Colorless & $38 \mathrm{~g}$ & $-98{ }^{\circ} \mathrm{C}$ \\
\hline Liquid Type 2 & $0.79 \mathrm{~g} / \mathrm{cm}^{3}$ & Colorless & $38 \mathrm{~g}$ & $26{ }^{\circ} \mathrm{C}$ \\
\hline Liquid Type 3 & $13.6 \mathrm{~g} / \mathrm{cm}^{3}$ & Silver Color & $21 \mathrm{~g}$ & $-39{ }^{\circ} \mathrm{C}$ \\
\hline Liquid Type 4 & $0.93 \mathrm{~g} / \mathrm{cm}^{3}$ & Colorless & $16 \mathrm{~g}$ & $-98{ }^{\circ} \mathrm{C}$ \\
\hline
\end{tabular}

Claim: Liquids 1 and 4 are the same substances.

Evidence: According to the table, the two liquids have the same properties for density, color, and melting point.

Reasoning: because the same substance has the same properties.

From studies on scientific reasoning in the perspective of argument or the creation of scientific explanations, it found that scientific reasoning had three key components: claims, evidence, and reasoning, and "reasoning". In this research, the researchers studied the ability to reason scientifically based on the following elements:

1) Claim refers to the answer to questions related to the phenomenon.

2) Evidence refers to scientific data used to support claims; this is derived from observing phenomena, facts, reading, discussions, experiments, and personal experiences.

3) Reasoning refers to the use of scientific principles to describe the relationship between evidence and claims. 
International Journal of Social Science and Economic Research

ISSN: 2455-8834

Volume:06, Issue:02 "February 2021"

\section{Theoretical concepts about the development of teaching models}

In the development of teaching models, there should be guidelines for developing the teaching model as effective as needed, which many educators have proposed to develop teaching models and procedures to develop teaching models, as follows:

Saylor et. al. (1981) proposes important principles for the developers of the teaching model to take into account as follows:

1) Goals and objectives, teaching model developers should take into account the teaching objectives, which determine the purpose of activities assigned to students to help achieve their goals, in general of teaching as much as possible. Therefore, the model to be developed must be consistent with the objectives and goals in general.

2) The high likelihood of achieving a goal, which the developers of the teaching model must take into account the possibility of achieving the goal. The level of feasibility depends on the consistency between the training activities in the course.

3) Student motivation, the effectiveness of the teaching model depends on the level of participation in the student's learning activities. Therefore, the developers of the model should provide activities that will motivate students to learn, perhaps by providing new materials that challenge students so that they do not get bored in their studies.

4) Learning principles, in the development of teaching patterns should not adhere to theory or learning principles alone, but should also apply many principles of learning in practice, such as intellectual development, motivation, reinforcement, attitude development, and basic human values.

5) Facilities, tools, and resources, teaching model developers must take into account the availability of tools, facilities, and resources needed to develop a teaching model.

Joyce and Weil (1996) proposed the following principles of the development of the teaching model:

1) Teaching patterns must be supported by theory, such as learning psychology theory.

2) Once the teaching model has been developed before it is widely applied, research is required to test the theory and monitor quality in terms of practical use and use the findings to improve the improved model.

3) The development of teaching models may be designed for widespread use or a particular purpose. 


\section{International Journal of Social Science and Economic Research}

ISSN: $2455-8834$

Volume:06, Issue:02 "February 2021"

4) The development of the teaching model is the main purpose of determining the model to be used, that is, if the user applies the teaching model to the main purpose, it will achieve the ultimate result, if it is considered appropriate, and it may be less successful.

\section{Concepts of teaching science}

Science is knowledge generated by intelligence and human efforts in education to understand what is happening on Earth and in the universe. Many study scientists describe the nature of science as a characteristic of science that differs from other sciences, including values, conclusions, concepts or explanations that indicate the scientist's career, the nature and behavior of scientists, knowledge and scientific concepts, as well as the effect of science on the American society for the advancement of science. The association of scientific research in the United States explains the nature of science in three areas: scientific worldview, scientific inquiry, and scientific affairs. In this regard, in teaching science, the focus is on students to discover the most self-knowledge, to obtain both process and knowledge from observation methods, surveys, examinations, and experiments, and then implement the results are systematically organized into principles, concepts, and knowledge (Institute for the Promotion of Teaching Science and Technology, 2017). Therefore, in teaching science to achieve course goals by using the theoretical teaching and learning management approach constructivism and the quest for scientific knowledge, so the details are as follows:

\subsection{Teaching science along with the constructivism}

Constructivism theory is based on the belief that students can build their knowledge, students will determine or participate in the determination of learning activities and mutual assistance, under the facilitation of the teacher. However, there have been educators who support the idea that "knowledge is self-created", there are two groups as follows: (Sumalee Chaicharoen, 2008)

1) Cognitive Constructivism, which is based on Piaget, "is a student who creates knowledge by taking action". Piaget believes that if a student is triggered by cognitive conflict or disequilibrium, students must try to improve cognitive structuring to equilibrium employing assimilation, and by obtaining new information from the environment into the intellectual structure into a balanced state, or being able to create new knowledge or learn.

2) Social constructivism is a theory rooted in Vygotsky, which has an important concept that "social interaction plays an important role in the development of intelligence", as well as the concept of "zone of proximal development". Vygotsky believes that students build knowledge through social interaction with others, including children, adults, parents, teachers, and friends, while children are in the context of social-cultural context. 


\section{International Journal of Social Science and Economic Research}

ISSN: $2455-8834$

Volume:06, Issue:02 "February 2021"

In the design of the management of learning along with constructivism, the two concepts are cognitive constructivism and social constructivism as follows: (Sumalee Chaicharoen, 2008).

1) Cognitive Constructivism, which manages cognitive constructivism, also known as Piagetism classrooms, is that students will have the opportunity to build knowledge through their own experiences, not from telling or teaching from teachers. On the other hand, it increases the emphasis on learning management in a meaningful context by adopting technology, especially multimedia, as a response to such learning activities. In this regard, the supported technologies include network media (Web-based), and CD-ROMs, where teachers can provide a learning environment that will help expand the basics of concepts, more conceptual and experiential experiences of students.

2) The social constructivism management model in all learning classes that correspond to Vygotsky's Social Constructivism may not necessarily hold all the same activities, events and patterns are subject to change as appropriate. However, four principles can be applied in a class called "Vygotskian" or according to social constructivism:

(1) Learning and development is a social aspect, namely collaborative activity.

(2) Zone of proximal development should meet the course preparation and planning of lessons.

(3) Learning in school should take place in a meaningful context and should not be separated from the learning and knowledge that students develop from real-world experiences outside of school that should be linked to their school experience.

\subsection{Teaching science along the way of the pursuit of knowledge}

According to the National Science Education Standards, the National Research Council (NRC, 2000) defines "Scientific Inquiry", said it is a research process used by scientists to study the phenomenon in nature, and present the results of the study based on the information or evidence gathered. Managing science learning by allowing students to learn in pursuit of knowledge means that students are involved in their learning processes, to develop an understanding of scientific content alongside process skills during the same search process that scientists use to understand natural phenomena. In other words, at the heart of the scientific quest in the classroom is to allow students to use the investigative process and gather information or evidence to explain the phenomenon or solve any problems or concerns they have to gain an understanding of the principles or scientific content. This, the quest for knowledge that students have done during science learning has a similar part to how scientists use it to learn things that interest them. 
International Journal of Social Science and Economic Research

ISSN: 2455-8834

Volume:06, Issue:02 "February 2021"

However, scientific inquiry consists of logical reasoning, empirical evidence, imagination, and creativity, as well as a search for explanations of interests, both personally and collectively, of people with the same interests. Therefore, scientific inquiry is more than a "scientific method" or "experiment", but rather a search for answers that interest it through the thoughtful but independent and non-static workflow. The key characteristics of the quest for scientific knowledge (Institute for the Promotion of Science and Technology, 2017) consist of (1) questions that can be answered or tested (2) evidence both empirical and from what others have discovered (3) understanding and analyzing data, then finding data relationships and creating explanations to answer questions of doubt (4) linking and comparing their descriptions with others, and (5) communicating the description or discovery to others.

\section{Conceptual Framework}

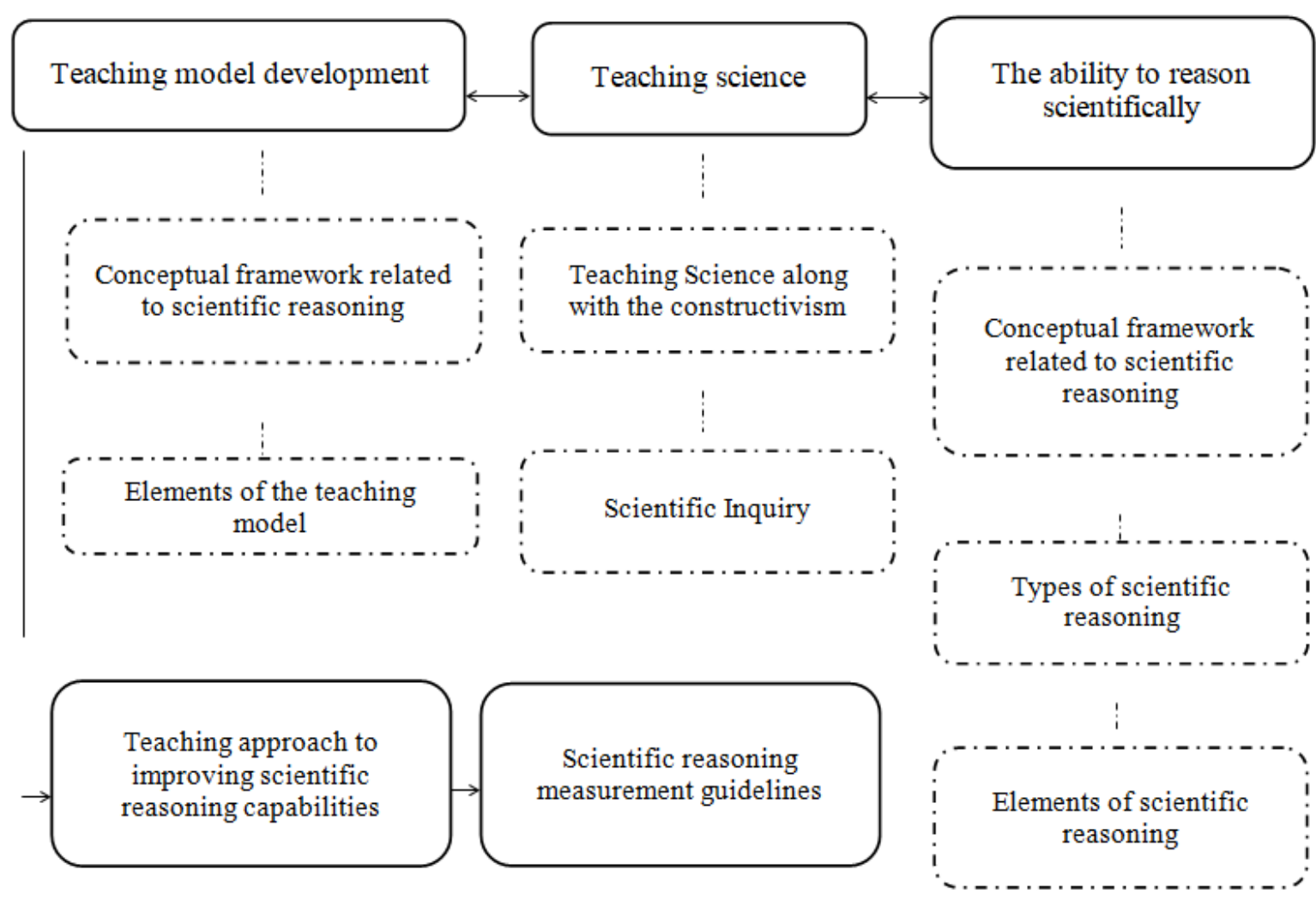

Figure 1:Research Framework

\section{Results}

\section{The results of creating a teaching model}


International Journal of Social Science and Economic Research

ISSN: 2455-8834

Volume:06, Issue:02 "February 2021"

The CODE teaching model developed by researchers is a teaching model used to promote the ability to provide scientific reasoning for high school students, detailed as follows:

\section{1) Principles of the CODE teaching model}

The teaching model developed by the researchers consists of three key principles, which are based on scientific inquiry.

(1) Learning is a process that occurs within an individual by linking existing knowledge with new experiences, it is a way of creating your understanding, and it is through the interaction between the learner and the learner, and between the teacher and the learner.

(2) Knowledge quest to obtain empirical evidence helps learners to adjust the intellectual structure.

(3) Allowing learners to participate in questioning, surveying, examination, reasoning using scientific data and evidence through interactions with friends and teachers, to help learners learn meaningfully.

\section{2) The aim of the teaching model}

The CODE teaching format has two objectives:(1) to develop the ability to give scientific reasons to learners, and (2) to provide students with the right understanding of physics concepts.

\section{3) Learning management process}

The CODE teaching model has 4 steps of learning management as follows:

Step 1: Concept test is a step in which the instructor presents questions about the concept to the learner while providing reasoning to test the original knowledge and the reasoning of the learner's knowledge of the physics phenomenon.

Step 2: Observation is a step in which participants observe and experiment or prove their understanding of physics phenomena with their friends, to obtain empirical evidence to explain the physics phenomenon.

Step 3: Discussion and discussion is the step in which participants discuss the results of observation or experimentation. The result may conflict with the original knowledge of the learner in the first place, or the reasoning is inconsistent with the scientific concept, in which the learner must create an explanation using evidence and reasoning to object or support the proposed claim, through mutual arguments between friends to gain an accurate understanding of physics phenomena. 
Step 4: Elaboration is to use new knowledge from the survey to link with the original knowledge or to draw conclusions to describe other situations or events.

\section{4) Learning management measurement and evaluation}

Measurement and evaluation according to the teaching model that CODE uses physical assessment as follows:

(1) The concept test is an assessment based on the learner's questions and reasoning about the physics phenomenon.

(2) Observation is an assessment based on the writing of experimental reports and behavioral observations during group activities.

(3) Discussion and reasoning is an assessment of the response of the question while discussing the results, the company focuses on the use of evidence for reasoning.

(4) Elaboration is an assessment of the answer and practice.

(5) Before and after learning by using a CODE teaching model, using a scientific reasoning ability test.

2. The results of the study results of the use of teaching patterns on the student's ability to give scientific reasoning

To study the results of using the CODE teaching model, the investigators compared the scores of scientific reasoning ability of the sample students between before and after the experiment, classified according to the situation, the results are as follows:

Table 1: Average score comparison results for students' scientific reasoning capabilities before and after trials.

\begin{tabular}{c|c|c|c|c|c}
\hline \multirow{2}{*}{ Subject } & \multicolumn{4}{|c|}{ Testing } & \multirow{2}{*}{ Effect Size } \\
\cline { 2 - 5 } & \multicolumn{2}{|c|}{ Pre-Test } & \multicolumn{2}{c}{ Post-Test } & \\
\cline { 2 - 5 } & $X$ & S.D. & X & S.D. & \\
\hline Projectile movement 1 & 8.71 & 2.79 & 15.14 & 3.53 & \multirow{2}{*}{2.0} \\
\hline Projectile movement 2 & 4.79 & 2.16 & 9.57 & 2.31 & \multirow{2}{*}{2.1} \\
\hline Vertical circular motion & 5.71 & 1.86 & 11.43 & 4.42 & \multirow{2}{*}{1.7} \\
\hline
\end{tabular}


International Journal of Social Science and Economic Research

ISSN: 2455-8834

Volume:06, Issue:02 "February 2021"

Circular motion horizontally

4.43

2.28

6.07

3.56

0.5

When comparing the number of students who can identify each element of scientific reasoning. This includes claims, evidence, and pre-test and post-test reasoning, which results in comparison, as follows:

Table 2: Percentage of student numbers that can identify reasoning elements

\begin{tabular}{|c|c|c|c|c|c|c|c|c|c|c|}
\hline \multirow{3}{*}{$\begin{array}{c}\text { Elements of } \\
\text { scientific } \\
\text { reasoning }\end{array}$} & \multicolumn{10}{|c|}{ Number of students (percent) } \\
\hline & \multicolumn{2}{|c|}{$\begin{array}{c}\text { Projectile } \\
\text { movement } 1\end{array}$} & \multicolumn{2}{|c|}{$\begin{array}{c}\text { Projectile } \\
\text { movement } 2\end{array}$} & \multicolumn{2}{|c|}{$\begin{array}{c}\text { Vertical } \\
\text { circular } \\
\text { motion } \\
\end{array}$} & \multicolumn{2}{|c|}{$\begin{array}{c}\text { Circular } \\
\text { motion } \\
\text { horizontally }\end{array}$} & \multicolumn{2}{|c|}{ Overall, it's } \\
\hline & pre & post & pre & post & pre & post & pre & post & pre & post \\
\hline Claim & 60.71 & 88.39 & 57.14 & 73.47 & 38.39 & 72.32 & 48.57 & 64.29 & 42.86 & 75.77 \\
\hline Evidence & 40.18 & 75.00 & 11.22 & 48.98 & 29.46 & 50.00 & 27.14 & 34.29 & 26.53 & 54.08 \\
\hline Reasoning & 8.04 & 25.89 & 0.00 & 14.29 & 3.57 & 20.54 & 12.86 & 22.86 & 5.61 & 20.92 \\
\hline
\end{tabular}

\section{Discussion}

The development of teaching models that enhance the ability to provide scientific reasoning for high school students, the researchers presented the results of the discussion as follows:

\section{Development of teaching models that enhance the ability to provide scientific reasoning for high school students.}

The development of teaching models that enhance the scientific reasoning capabilities of high school students, researchers use constructivism theory concepts, and the pursuit of knowledge as a base for development, which aims to develop the ability to provide scientific reasoning and understanding of the scientific concepts of learners, there are 4 steps: step 1, concept test, step 2 observation, step 3 discussion and reasoning, and step 4 of elaboration. The quality of the teaching model scrutinized by the experts and the trial, before applying the sample, is consistent with Joyce and Weil (2009), who say that in the development of teaching models, there must be a theory to support, once the teaching model has been developed before it is widely applied, research is required to test the theory and monitor quality in terms of practical use and to improve the development of the development.However, this evolving teaching model focuses on students conducting surveys to obtain empirical evidence in support of claims, this is in line with Zimmerman (2007) and Bao et. al, (2009), who says that learning science-based on knowledgebased search can help promote the ability to use scientific reasons. However, to implement this 


\section{International Journal of Social Science and Economic Research}

ISSN: 2455-8834

Volume:06, Issue:02 "February 2021"

teaching model, teachers must have an understanding of scientific concepts and understand the elements of scientific reasoning and should take into account the basic level of knowledge or original knowledge of the learner.

\section{Studying the results of the use of teaching models that strengthen the ability to give scientific reasoning.}

The results showed that the scientific reasoning ability of the experimental group students who studied with the post-experimental CODE teaching model was higher than before in all subjects, considering the elements of scientific reasoning, it found that students were able to identify all elements of their ability to reason scientific reasons in all subjects if the course process was considered. It was found that the CODE teaching model focused on students answering questions and reasoning by using prior knowledge in the previous knowledge survey. The reasoning of the student's reasoning shows the student's misguided ideas, and then the students conduct a survey to obtain evidence of their original objection or support of their original knowledge, and then bring the survey results to the discussion and give reasons together with their friends, this is based on scientific principles described to link the relationship between evidence and claims.At this stage, students exchange knowledge and opinions with each other, as well as adjust or modify their misleading ideas. This is consistent with the concept of Piaget (1985 referred to in Marusic \& Slisko, 2012), who said that in a person's learning, two different processes are occurring: assimilation. This is a process in which a person uses an existing cognitive structure to understand new events, and intellectual restructuring (accommodation). This is a current cognitive restructuring to reinterpret your experience or situation. When students experience new experiences for the first time, they will try to understand the new experience using the same knowledge, and when it appears that it is not appropriate for existing knowledge structures, and cognitive imbalances or intellectual conflicts arise, learners will need to adapt their concepts until they can integrate new experiences into the original experience.

In this regard, considering the composition of scientific reasoning, it is found that the composition of claims is the most identifiable element that students can identify because they are the elements that students use to share their original knowledge about the phenomenon of choice. This is consistent with the results of Ruiz-Primo, Li, Tsai, and Schneider (2010), which found that the claims were an element of creating scientific explanations that students could most easily identify, compared to data and reasoning elements. However, the ability for students to correctly identify claims may be due to the nature of the test as multiple-choice, students who guess the answer have a chance to get the right answer as well. As for the evidence, it was found that the student's constituents were able to identify the second part of the claim. However, this is the first time that this element requires students to consider whether the evidence they use to support the 


\section{International Journal of Social Science and Economic Research}

ISSN: $2455-8834$

Volume:06, Issue:02 "February 2021"

claims is accurate and appropriate. According to the student's reasoning examination, it was found that some students did not understand that in reasoning, evidence was required to assemble. Students use evidence to support inaccurate claims because this element is more difficult than the composition of the claims, students must consider whether the information found from the trial can be used to support the claims. This can be seen if the data from the experiment has several data. Students can't use the information to support their claims. This gives students the lower ability to this element than the element of the claims, and in terms of reasoning, it is found that the least identifiable element of the student is that in reasoning, students must use scientific principles to provide explanations to link the relationship between claims and evidence. Which, Lawson (2003 referred to in Lee \& She, 2010), discusses the relationship between a learner's misguided concept and the ability to reason that to modify that misconception. Therefore, learners need to be aware of their misguided concepts and scientific concepts, using evidence and reasons to demonstrate the validity of the misguided concept.In other words, they must be rational in determining how the evidence supports scientific concepts and contradicts previous misguided understandings, in which scientific reasoning is used in arguments to eliminate the misguided concepts of learners before obtaining the right scientific concepts.

\section{Suggestion}

Research on the development of teaching models that enhance the ability to provide scientific reasoning for high school students, the researchers presented feedback from the research, as follows:

1. In teaching science, teachers should focus on students to answer causal questions. This is to explain the scientific phenomenon by using reasoning to link the relationship between evidence and claims.

2. Teachers should encourage students to be aware of the importance of providing evidence in support of their claims, and use arguments to reach accurate conclusions consistent with scientific concepts.

3. To present a scientific issue should be a problem that students can see in everyday life, experiments can be conducted to prove the claim easily, and the student's original knowledge should be taken into account before designing the teaching activities.

\section{Reference}

Bao, L., Cai, T., Koenig, L., Fang, K., Han, J., Wang, J., and Wu, N. (2009). Physics:

Learning and scientific reasoning. Science, 323(5914), 586-587. 


\section{International Journal of Social Science and Economic Research}

ISSN: $2455-8834$

Volume:06, Issue:02 "February 2021"

Berland, L. K., McNeill, K. L., Pelletier, P., \& Krajcik, J. (2017). Engaging in argument from evidence. In C. V. Schwarz, C. Passmore, \& B. J. Reiser (Eds.), Helping students make sense of the world using next generation science and engineering practices (pp. 229257). Arlington, TX: National Science Teacher Association.

Chaicharoen, S. (2008). Educational technology and teaching system development. Khon Kaen: Khon Kaen University.

Dennick, R. (2016). Constructivism: Reflections on twenty five years teaching the constructivist approach in medical education. International Journal of Medical Education, 7, 200-5.

Develaki, M. (2017).Using computer simulations for promoting model-based reasoning. Epistemological and educational dimensions. Science \& Education, 26, 1001-10027.

Ding, L., Wei, X., \& Mollohan, K. (2016). Does higher education improve student scientific reasoning skills?. International Journal of Science and Mathematics Education, 14(4), 619-634.

Engelmann, K., Neuhaus, B., \& Fischer, F. (2016). Fostering scientific reasoning in education meta-analysis evidence from intervention studies. Educational Research and Evaluation, 22(5-6), 333-349.

Fabby, C., \& Koenig, K. (2015). Examining the relationship of scientific reasoning with physics problem solving. Journal of STEM Education: Innovations \& Research, 16(4), 141-144.

Fischer, F., Kollara, I., Uferb, S., Sodiana, B., Hussmannc, H., Pekruna, R., Eberlea, J. (2014). Scientific reasoning and argumentation: Advancing an interdisciplinary research agenda in education. Frontline Learning Research, 5, 28-45.

Giere, R. (1991). Understanding scientific reasoning (3rd ed.). Fort Worth, TX: Harcourt Brace Jovanovich.

Gotwals, A. W., Songer, N. B., \& Bullard, L. (2012). Assessing students' progressing abilities to construct scientific explanations. Learning progressions in science, (183-210)

Ibrahim, B., Ding, L., Mollohan, K. N., \& Stammen, A. (2016). Scientific Reasoning: Theory evidence coordination in physics-based and non-physics-based tasks. African Journal of Research in Mathematics, Science and Technology Education, 20(2), 93-105. 


\section{International Journal of Social Science and Economic Research}

Institute for the Promotion of Teaching Science and Technology. (2017). Course Manual Basic Science Courses Primary level. Bangkok: Institute for the Promotion of Teaching Science and Technology.

Institute for the Promotion of Teaching Science and Technology. (2017). Research Report of TIMSS Project 2015. Bangkok: Institute for the Promotion of Teaching Science and Technology.

Jensen, J. L., \& Lawson, A. (2011). Effects of collaborative group composition and inquiry instruction on reasoning gains and achievement in undergraduate biology. $\mathrm{CBE}$ Life Sciences Education, 10, 64-73.

Joyce, B.R. and Weil, M. (1996). Model of teaching (5th ed.). New York: Prentice Hall.

Joyce, B., Weil, M., \& Calhoun, E. (2009). Models of teaching (8thed.). New York: Courtesy of Reece Galleries.

Jufri, A. W., Setiadi, S., \& Sripatmi, D. (2016). Scientific Reasoning Ability of Prospective Student Teacher in The Excellence Program of Mathematics and Science Teacher Education in University of Mataram. Journal Pendidikan IPA Indonesia, 5(1), 69-74.

Krajcik, J. \& McNeill, K. L. (2015). Developing and assessing scientific explanation tasks. In Gunstone, R. (Ed.). Encyclopedia of science education (pp. 285-291). Dordrecht: Springer Netherlands.

Kuhn, D., \& Pearsall, S. (2000). Development origins of scientific thinking. Journal of Cognition and Development, 1, 113-127.

Lawson, A. E. (1985). A review of research on formal reasoning and science teaching. Journal of Research in Science Teaching, 22(7), 569-617.

Lawson, A. E. (2000). Development and validation of the classroom test of formal reasoning Revised Edition. Arizona State University.

Lee, C. Q., \& She, H. C. (2010).Facilitating students' conceptual change and scientific reasoning involving the unit of combustion. Research in Science Education, 40(4), 479-504.

Martin, M., Mullis, I., Foy, P., \& Stanco, G. (2012). TIMSS 2011 international results in science. Chestnut Hill, MA: TIMSS \& PIRLS International Study Center, Boston 


\section{International Journal of Social Science and Economic Research}

ISSN: $2455-8834$

Volume:06, Issue:02 "February 2021"

College.

Marusic, M., \& Slisko, J. (2012). Influence of three different methods of teaching physics on the gain in students' development of reasoning. International Journal of Science Education, 34(2), 301-326.

McNeil, K. \& Krajcik, J. S. (2008). Inquiry and scientific explanations: Helping students use evidence and reasoning. In J. A. Luft, R. L. Bell \& J. Gess-Newsome (Eds.), Science as inquiry in the secondary setting. Arlington: NSTA press.

National Research Council. (2000). Inquiry and the national science education standards: A guide for teaching and learning. Washington DC: National Academy.

Piekny, J., \& Maehler, C. (2013). Scientific reasoning in early and middle childhood: The development of domain-general evidence evaluation, experimentation, and hypothesis generation skills. British Journal of Developmental Psychology, 31, 153-179.

Peters, E. (2012). Beyond comprehension: The role of numeracy in judgments and decisions. Current Directions in Psychological Science, 21, 31- 35.

Ruiz-Primo, M. A., Li, M., Tsai, S. P., \& Schneider, J. (2010). Testing One Premise of Scientific Inquiry in Science Classrooms: Examining Student, Scientific Explanations and Student Learning. Journal of Research in Science Teaching, 47(5), 583-608.

Saylor, Galen J., William M. Alexander, and Arthur J. Lewis. (1981). Curriculum Planning for Better Teacher and Learning (4th ed.). New York : Holt Rinehart and Winston.

She, H. C., \& Liao, Y. W. (2010). Bridging scientific reasoning and conceptual change through adaptive web-based learning. Journal of Research in Science Teaching, 47(1), 91-119.

Taasoobshirazi, G., \& Sinatra, G. M. (2011). A structural equation model of conceptual change in physics. Journal of Research in Science Teaching, 48, 901-918.

Toulmin, S. E. (2003). The Uses of Argument (updated edition). Cambridge: Cambridge University Press.

Wilson, C., Taylor, J., Kowalski, S., \& Carlson, J. (2010). The relative effects and equity of inquiry-based and commonplace science teaching on students' knowledge, reasoning, and argumentation. Journal of Research in Science Teaching, 47(3), 276-301. 
Yang, H.-T., \& Wang, K.-H. (2014). A teaching model for scaffolding 4th grade students' scientific explanation writing. Science Education, 44, 531-548.

Zeineddin, A., \& Abd-El-Khalick, F. (2010). Scientific Reasoning and Epistemological Commitments: Coordination of Theory and Evidence Among College Science Students. Journal of research in science teaching, 47(9), 1064-1093.

Zhou S., Han J., Koenig K., A., Pi Y., Li D., \& Bao L. (2016). Assessment of Scientific Reasoning: The Raplinger Effects of Task Context, Data, and Design on Student Reasoning in Control of Variables. Think. Skills Creat., 19, 175-187.

Zimmerman, C. (2007). The development of scientific thinking skills in elementary and middle school. Developmental Review, 27, 172-22. 